\section{Pediatric and adolescent gynecology: Treatment perspectives in minimally invasive surgery}

Gloria Pelizzo, ${ }^{1}$ Ghassan Nakib, ${ }^{2}$ Valeria Calcaterra $^{3}$

1 Pediatric Surgery Department, Children's Hospital, ARNAS Civico-Di

Cristina-Benfratelli, Palermo, Italy;

${ }^{2}$ Department of Pediatric Surgery, Mediclinic Middle East, Mediclinic City Hospital Dubai, UAE; 3Pediatric Unit, Department of Maternal and Children's Health, Fondazione IRCCS Policlinico San Matteo and Department of Internal Medicine, University of Pavia, Italy

\begin{abstract}
Minimally invasive surgery (MIS) is widely utilized across multiple surgical disciplines, including gynecology. To date, laparoscopy is considered a common surgical modality in children and adolescents to treat gynecological conditions. Robotic surgical devices were developed to circumvent the limitations of laparoscopy and have expanded the surgical armamentarium with better magnification, dexterity enhanced articulating instruments with 5-7 degrees of freedom, and ability to scale motion thus eliminating physiologic tremor. There are well-documented advantages of MIS over laparotomy, including decreased post-operative pain, shorter recovery times, and better cosmetic results. Indications for MIS in pediatric gynecology are reported in this review and technical considerations are described to highlight new treatment perspectives in children and adolescents, which have already been described in the literature regarding adult patients.
\end{abstract}

\section{Introduction}

Minimally invasive surgery (MIS) is widely utilized across multiple surgical disciplines, including gynecology. ${ }^{1-5}$ Currently, laparoscopy is considered the standard of care in the management of many gynecologic conditions in adults; and in the last decade this procedure has also offered a common surgical modality in children and adolescents. ${ }^{6-10}$

Some of the limitations of laparoscopy are reduced depth perception of the operative field caused by the use of 2D monitors, poor hand-eye coordination as a result of the monitor position, variable amplification, mirrored movement and misorientation, motion limitations due to trocar-induced invariant points, and reduced haptic feedback from the use of long and slender surgical instruments. ${ }^{11-14}$ The robotic surgical device was developed to circumvent the limitations of laparoscopy and has expanded the surgical arsenal with better magnification, dexterity enhanced articulating instruments with 5-7 degrees of freedom, and the ability to scale motion thus eliminating physiologic tremor. ${ }^{11-14}$ Robotic gynecologic surgery provides additional benefits over other approaches in highly complex cases, ${ }^{6,8-10}$ particularly in small and narrow spaces, such as the pelvis, even though randomized controlled trials comparing robotic surgery with conventional laparoscopy are limited in the pediatric age and there is a lack of evidence showing superiority or clear indications for its use. The advantages of MIS over laparotomy are well-documented, and include decreased post-operative pain, shorter recovery times, and better cosmetic results.

In this review, indications for MIS in pediatric gynecology are reported and technical considerations are described to highlight new perspectives of treatment in children and adolescents, which have already been described in the literature in adult patients.

\section{Indications for mininvasive gyne- cological procedures in the pedi- atric age}

Treatment of gynecologic pathologies in the pediatric population include adnexal, uterine and peritoneal procedures (Table 1). ${ }^{15}$

\section{Adnexal masses}

The estimated incidence of adnexal masses is approximately 2.6 cases in 100,000 girls in childhood; rates in adolescents are suspected to be higher, but precise population-based estimates are lacking. 16 The differential diagnosis for an adnexal mass is lengthy and includes the evaluation of non-genitourinary organ systems (Table 2).

The majority of the adnexal masses in females aged 2 days to 21 years are cysts, predominately hemorrhagic corpus luteal cysts.

The remaining masses are neoplasms, of which $75 \%$ are benign. ${ }^{17-21}$ Ovarian masses that are $<10 \mathrm{~cm}$, primarily cystic, and have negative tumor markers are most likely benign. ${ }^{22-28}$ The most common benign mass in young females is cystic teratoma. ${ }^{21,29-31}$
Correspondence: Gloria Pelizzo, Pediatric Surgery Department, Children's Hospital, ARNAS Civico-Di Cristina-Benfratelli, Via dei Benedettini 1, 90134 Palermo, Italy.

E-mail: gloriapelizzo@gmail.com

Key words: Pediatric; adolescent; gynecology; minimally invasive surgery; pediatric surgery.

Acknowledgments: the authors thank Dr. L. Kelly for English revision of the manuscript.

Contributions: GP conception and design, expertise in surgical data, manuscript writing, supervision manuscript, final approval of manuscript, GN conception and design, expertise in surgical data, manuscript writing, final approval of manuscript, $\mathrm{VC}$ conception and design, literature revision, manuscript writing, final approval of manuscript.

Conflict of interest: The authors declare no potential conflict of interests.

Funding: none.

Received for publication: 8 February 2019 .

Revision received: 4 September 2019.

Accepted for publication: 5 September 2019.

This work is licensed under a Creative Commons Attribution NonCommercial 4.0 License (CC BY-NC 4.0).

CCopyright: the Author(s), 2019

Licensee PAGEPress, Italy

Pediatric Reports 2019; 11:8029

doi:10.4081/pr.2019.8029

Malignant ovarian tumors in the pediatric age are rare, accounting for only $1.1 \%$ of all malignancies in female patients less than 15 years of age. $25,32,33$ Oltman et al.,34 reported the best predictive preoperative indicators of an ovarian malignancy: complaint of a mass or precocious puberty, mass exceeding $8 \mathrm{~cm}$ or a mass with solid imaging characteristics. Patients aged 1 to 8 years have the greatest incidence of malignancy. Tumor markers, positive or negative, are not always conclusive in all cases, but are useful for postoperative surveillance. ${ }^{34}$

Germ-cell tumors are the most common malignancy in children and adolescents and are typically found in girls between the age of 8 and 15 years. The tumor staging system suggested by the Children's Oncology Group (Table 3) is usually used to determine treatment. 35,36 Large case series of ovarian masses in children and adolescents have found that $60 \%$ to $70 \%$ of patients present with abdominal complaints, typically abdominal pain. 15 Even though, ovarian 
masses can be asymptomatic, they may be discovered on routine physical examination as a palpable mass or present with other symptoms. ${ }^{20,24,29,37}$ When an adnexal mass is suspected or palpated, imaging should be obtained.26,37,38 Ultrasound is the preferred imaging modality when an ovarian mass is suspected due to its superior resolution as compared with computerized tomography and its ability to assess vascular flow patterns. Features observed with ultrasound that should raise suspicion of a malignancy include: a solid component often described as papillary or nodular, vascular flow within the solid component, thick $(>3 \mathrm{~mm})$ septation and the presence of ascites. ${ }^{15,17,37,39}$ Tumor markers, including cancer antigen125, $\alpha$-fetoprotein, lactate dehydrogenase, human chorionic gonadotropin, inhibin, Müllerian inhibiting substance, and carcinoembryonic antigen, can be obtained preoperatively if there is a suspicion of malignancy. $19,27,32,37$

Management of ovarian cysts is dependent on the size of the cyst and the presence of symptoms. Small simple cysts, less than $2 \mathrm{~cm}$, should be regarded as normal and require no intervention. Cysts larger than $2 \mathrm{~cm}$ without symptoms should be observed expectantly, with sonographic follow-up. Ovarian cysts that enlarge, become symptomatic, demonstrate signs of hormonal activity, or have malignant features should be managed operatively. 17,20,29

Due to the extremely low frequency of malignant ovarian neoplasies in children and adolescents, ${ }^{17-21,29}$ the laparoscopic or robotic resection of an ovarian cyst offers a safe operative approach with good cosmetic results, an important factor, especially in this group of patients. ${ }^{14} \mathrm{MIS}$, even in the case of a benign cyst with great dimensions, offers good outcomes without further complications. All surgical procedures for ovarian cysts should spare the functional ovary as much as is technically possible. Cystectomy or fenestration are the treatments of choice for simple cysts. Complex or functional cysts should be excised, with the preservation of the remaining ovary. 18,30

Masses exhibiting suspicious signs of malignancy should generally be excised by laparoscopic oophorectomy. In fact,

Table 1. Indications for mininvasive gynecological procedures.

\begin{tabular}{ll} 
& \multicolumn{1}{c}{ Type of procedure } \\
Adnexal procedure & Adnexal cystectomy(ies), cyst drainage, detorsion \\
& Gonadectomy (unilateral or bilateral) \\
& Oophoropexy \\
& Ovarian debulking \\
& Salpingectomy, salpingostomy \\
& Salpingo-0ophorectmy \\
& Excision of uterine horn remnant(s) \\
Uterine procedure & Excision of uterine mass \\
\hline Peritoneal procedure & Excision of peritoneal implant(s) suggestive of endometriosis \\
\hline
\end{tabular}

Table 2. Differential diagnoses of adnexal masses in the pediatric age.

\begin{tabular}{ll} 
Ovarian and tubal lesions & \multicolumn{1}{c}{ Adnexal masses } \\
& Functional cyst, paraovarian/paratubal cyst \\
& Ovarian tumor \\
& Hydrosalpinx, tubo-ovarian abscess, ectopic pregnancy \\
Uterine lesions & Leiomyoma, hematometra \\
\hline Urinary lesions & Pelvic kidney, urachal cyst, hydronephrosis, tumors (eg, Wilms tumor) \\
Intestinal lesions & Periappendiceal abscess \\
& Mesenteric cyst \\
\hline
\end{tabular}

Table 3. Ovarian germ cell tumor staging (modified according to the Children's Oncology Group staging) and event free survival (EFS).35,36

\begin{tabular}{|c|c|c|}
\hline Stage & Staging criteria & 5-years EFS \\
\hline I & $\begin{array}{l}\text { Disease limited to the ovary and completely excised; negative peritoneal washing. } \\
\text { No clinical, surgical, histological, or radiographic evidence of disease outside of the ovary } \\
\text { (the presence of gliomatosis peritonei does not result in a stage change). } \\
\text { Tumoral markers and/or hormonal levels in range after surgery. }\end{array}$ & $72.1 \%$ (95\% CI: $56.4-92.1 \%)$ \\
\hline II & $\begin{array}{l}\text { Microscopic residuals, spillage or nodes affected by disease }(<2 \mathrm{~cm}) \text {, negative peritoneal washing. } \\
\text { Tumor markers positive or negative. }\end{array}$ & 91.1\% (95\% CI: 83.1-99.9\%) \\
\hline III & $\begin{array}{l}\text { Macroscopic residuals or initial biopsy only; contigous visceral involvement } \\
\text { (omentum, intestine and bladder); positive peritoneal washing; lymph mode involvement ( }>2 \mathrm{~cm} \text { ). } \\
\text { Tumor markers positive or negative. }\end{array}$ & 91.1\% (95\% CI: 83.1-99.9\%) \\
\hline IV & Distant metastases, including the liver. Tumor markers positive or negative. & 91.1\% (95\% CI: 83.1-99.9\%) \\
\hline
\end{tabular}


oophorectomy minimizes the risk for spillage of the cyst contents compared with cystectomy. Spillage of malignant cysts leads to the dissemination of cells within the peritoneum, which increases the patient's tumor stage. When oophorectomy can be carried out, no salpingectomy is required, which is preferable in this age group. 18,19,24,26,40

A minimally invasive surgical approach is also considered when adnexal torsion occurs with benign functional ovarian cysts and/or benign masses. The detorsion and preservation of the adnexal structures is recommended in pediatric age. A torsed ovary must not be removed unless oophorectomy is unavoidable, such as when a severely necrotic ovary falls apart. 40

Even though in adults, robotics represents a major scientific breakthrough in surgical management of gynecological cancer,41-43 data on the management of ovarian cancers remains debated and to date are limited in the pediatric age.

\section{Peritoneal procedures}

\section{Endometriosis}

Endometriosis is a common benign and chronic gynecologic disorder related to the presence of endometrial glands and stroma outside of their normal location. ${ }^{44}$ The disease often begins in adolescence, but is most often recognized after years of dysmenorrhea. The prevalence of endometriosis in the general population is estimated to be between 0.7 and $44 \%$. The true incidence of endometriosis in adolescents is difficult to quantify and estimates vary among different studies. 45 Goldstein et al. 46 reported a $47 \%$ incidence of disease in adolescent girls undergoing laparoscopy for chronic pelvic pain; whereas, Laufer et al.47 reported endometriosis in $67 \%$ of adolescents who had pain refractory to common medical treatments at the time of surgery.

There are a variety of methods that can be used to assess whether a girl has endometriosis. In adolescents, the primary symptom of endometriosis is chronic pelvic pain (often acyclical); while, bowel and bladder symptoms are also common in adolescents. ${ }^{48}$ The diagnostic procedure does not differ in adolescents or adults, but a careful history is crucial in young women to determinate the chronicity of the pain and responsiveness to drugs.

Pelvic ultrasound remains a cornerstone in the diagnosis of this disease, although it is less helpful in adolescents as endometrioma is rare in adolescents. An MRI examination is a better diagnostic tool, but the elevated cost makes it less accessible.49,50
Endometrial biopsy with assessment of the amount of nerve fibers has recently been reported as a successful approach.

The biochemical markers of this disease have been known for years, and new developments may permit a noninvasive and timely diagnosis. CA 125 , Ca 19.9, ICAM1 , and IL-6 together with follistatin and urocortin have proven to be the most reliable markers for endometriosis diagnosis. 48,51 However, the only reliable way to confirm the disease is by visually inspecting the abdominal organs and biopsy using laparoscopic methods.

The first-line therapy in adolescents with endometriosis is oral contraceptives and analgesics. Unfortunately, many patients do not respond to this therapy. The alternative options are either therapy with $\mathrm{GnRH}$ analogues (only in patients over 18 years) or surgery. ${ }^{48-51}$

Laparoscopy is considered the fundamental therapeutic tool for endometriosis, when pharmacological treatment is not successful. The laparoscopic approach to lesions allows also for a definitive diagnosis. ${ }^{52,53}$ Medical treatment is always recommended after surgical removal to prevent recurrences. ${ }^{54}$

Several studies have demonstrated the feasibility of robotic surgery for deep infiltrating endometriosis. Importantly, robotic surgery has many advantages over the gold standard laparoscopic approach particularly the improved visualization in narrow spaces, especially for children. 55,56

\section{Uterine procedures}

\section{Excision of uterine horn remnant(s)}

Approximately $7 \%$ of girls will present with a Mullerian anatomic abnormality, diagnosed before or after puberty. ${ }^{57,58}$ In Table 4, the American Society of Reproductive Medicine 59 classification of anomalies is provided.

Such anatomic problems result in a nonobstructive outflow tract without pain or outflow tract obstruction with pain. Besides the history and presence of physical traits reported in the above-mentioned classification, imaging is an important part of the diagnostic process in Mullerian anomalies. ${ }^{58}$ Usually the first imaging modality is ultrasonography. Since a transvaginal approach is often not tolerated or even possible in this population, transabdominal ultrasonography is an appropriate initial imaging modality. Traditionally the MRI is considered the gold standard for a precise diagnosis.60 More recently, 3D ultrasonography has been used due to the high cost and patient inconvenience associated with MRI; however, there is not enough data available to judge its superiority in comparison with MRI at this time. 61

In any case of reproductive tract abnormalities involving Mullerian structures, there is a high incidence of renal (40\%) and spinal (10\%-20\%) abnormalities. It is important to use additional imaging, such as renal ultrasonography or abdomen MRI and spinal radiography, to screen for these problems depending on the underlying diagnosis. 60

The laparoscopic approach, which allows for a shorter recovery, improved postoperative pain and cosmesis, has been used for obstructive Mullerian anomalies. Laparoscopy is used for removal of uterine remnants in patients with MayerRokitansky-Kuster-Hauser syndrome (MRKH) and in patients with unicornute uteri. Particularly in MRKH, this procedure poses unique challenges due to the aberrant anatomy, lateral displacement of uterine remnants, altered vascular pedicle, associated urinary tract anomalies, and possible endometriosis with resulting adhesions. When remnants are displaced laterally on the pelvic sidewall, medial traction of uterine remnants is important to prevent injury to pelvic sidewall structures and in particular to the ureters. A regular grasper can be used for the smaller remnants, although the laparoscopic $5 \mathrm{~mm}$ tenaculum is sometimes required to obtain a good grasp of larger remnants. Surgical management of associated endometriosis should be individualized. 57

Uterine remnant removal is usually

Table 4. Classification systems for congenital uterine anomalies according to American Society of Reproductive Medicine.59

\section{Class Müllerian Structure Type}

I Agenesis, dysgenesis, or atresia

II Unicornuate uterus with or without communicating or non-communicating horn associated

III Didelphic uterus

IV Bicornuate uterus or arcuate uterus

$\mathrm{V} \quad$ Septate uterus (partial or complete)

VI DES-exposed 
managed with conventional laparoscopy, and the robotic laparoscopy technique has also been considered to improve visualization and ease of sewing defects into layers. ${ }^{14}$

\section{Excision of uterine mass}

Uterine masses are extremely rare in adolescence, with few reports found in the literature. Limited cases of uterine leyomioma, ${ }^{62,63}$ leiomyosarcomas 64 and Müllerian adenosarcomas ${ }^{65,66}$ are reported.

Regarding the treatment of uterine masses occurring during adolescence, experience is limited to the published cases, and there are no guidelines that shed light specifically on this situation. Uterine preservation, with the objective of preserving fertility are recommended and laparoscopic techniques are used in adolescents. There are no data on the applicability of robotics in uterine mass excision in this group of patients, even though the favorable experience in adults 67,68 supports this approach also in the pediatric age.

\section{Surgical approach and technical considerations}

\section{Patient positioning}

Positioning of the patient is important for successful surgical outcomes. ${ }^{69}$ Correct positioning provides better exposure of the operative site, especially in small infants. 69 For the gynecological procedure, the patient is placed in a dorsal supine position as for abdominal laparoscopic surgery and the lithotomy position is necessary when a combined perineal approach might be indicated. Frequently and especially in low weight or small children, the "frog leg" position is used; in this position the child lies obliquely on the table, offering better ergonomics to the surgeon. Positioning is important to avoid any possible muscle or nerve injuries as well as maintain circulation. In pediatric robotic surgery, the extreme positioning usually adopted in adults to gain maximum exposure to the surgical site, ${ }^{69}$ is not required in children. This extreme position helps displace the patient's abdominal viscera upward, which improves the surgeon's view of the anatomy of the lower abdomen and pelvis. The Trendelenburg position, when needed, should be used only after the main trocar has been inserted as this is always done through an open incision.

The Foley catheter is a must for all pelvic procedures. The surgeon should keep in mind that the bladder in infants and small children is abdominal; so, to avoid any bladder injury, the pelvic trocar must be inserted under scope vision.

In most procedures the arms are tucked along the body and fixed, so the surgeon is positioned at the shoulders of the patient. The surgeon will stand at the left shoulder if the operative field is at the right side of the pelvic area, at the right shoulder if the field is at the left pelvic area. This will provide the best ergonomic approach for the surgeon.

During the robotic approach, positioning of the robotic dual-console, robot, scrub station and anesthesia machines should be optimized to ensure the most effective arrangement for seamless work flow. A schematic of the room setup for gynecological procedures in children and adolescents is illustrated in Figure 1. The surgeon performs the procedure from the da Vinci Si Surgical System ${ }^{\circledR}$ console, while the surgical assistant standing at the patient's right or left side is ready to prepare special introduction sites depending on the nature of the pathology.

\section{Instrumentation}

\section{Laparoscopy instrumentation}

The availability of 2.5- and 3-mm mini instruments revolutionized laparoscopic gynecologic procedures, which is now the first-choice approach in most gynecologic procedures. The complete set of laparoscopic instruments required should include the following.

\section{Electronic $\mathrm{CO}_{2}$ endoflator}

An insufflation unit is used to deliver $\mathrm{CO}_{2}$ into the peritoneal cavity. In pediatric laparoscopy, the volume required should not exceed 3-4 L/min and pressures should be kept between 6 to $12 \mathrm{mmHg}$.

\section{Trocars}

Trocars to access the peritoneal cavity are available in different materials, designs and sizes: (sharp, blunt or pyramidal tip; and can be disposable or reusable).

The primary trocar accommodates the laparoscope. In the case when an operative scope is required, 5 to $10 \mathrm{~mm}$ trocars are used. It is introduced through an open incision via the umbilicus; while $3 \mathrm{~mm}$ to 5 $\mathrm{mm}$ trocars are introduced under vision at the requested sites.

\section{Endoscopes}

Endoscopes are available in various diameters and lengths. A cold light source is required and the $10 \mathrm{~mm}$ laparoscope is preferable as it permits a high-quality image of the organs and close-up views. The laparoscope is also available with different angles of view: $0^{\circ}$ and $30^{\circ}$ degrees.

The $0^{\circ}$ degree is most widely used in gynecologic procedures, even if a $30^{\circ}$ oblique laparoscope can be used in cases with difficult anatomical conditions.

\section{Recording system}

A digital data archiving system is used. Intaroperative data is archived on a DVD or USB stick. High definition video technology is used for visualization on flat screens and recording.

\section{Camera, light source and cables}

An adequate level of illumination must be maintained during the whole procedure. This is accomplished using a cold light source and cable that deliver the quantity of light needed.

\section{Forceps, scissors and needle holders}

A set of instruments that meets the anatomical and ergonomic requirements is

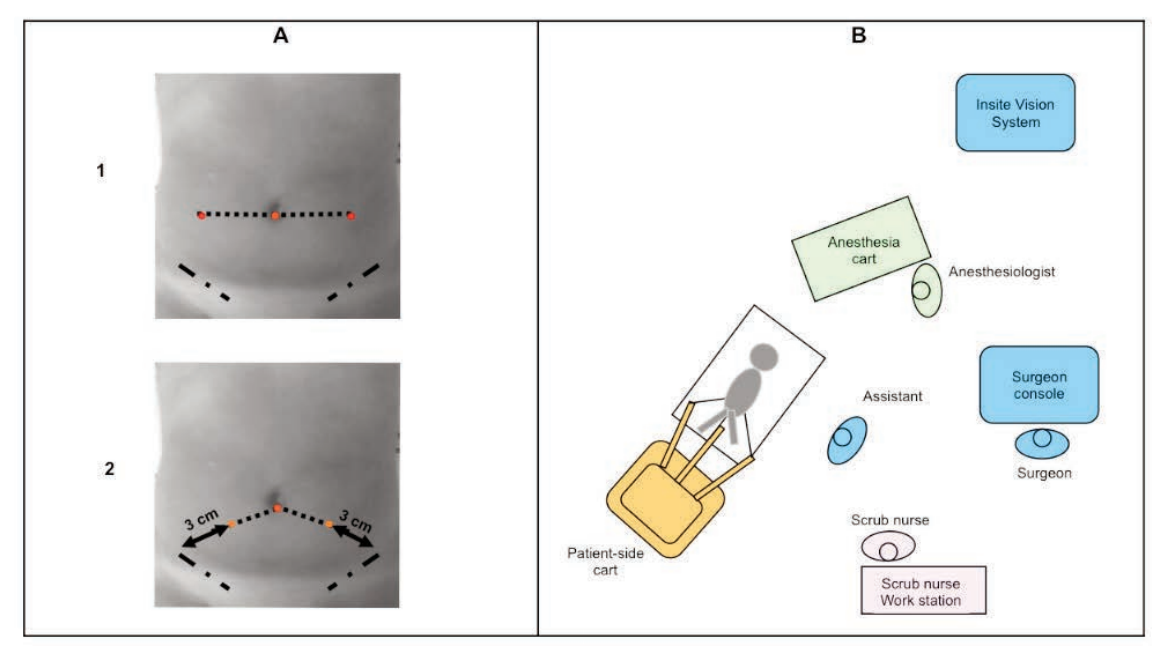

Figure 1. Room setup schematic for gynecological procedures. Panel A: trocar positioning in small children $(<8$ years, Panel A1) and in children ( $>8$ years, Panel A2) and adolescents. Panel B: position of the surgical staff and robot components. 
fundamental in pediatric gynecologic procedures. These can be of different lengths and diameter sizes, $3 \mathrm{~mm}$ or $5 \mathrm{~mm}$ and are usually reusable. Atraumatic, dissecting and grasping forceps with a connector pin are used for unipolar coagulation. Electrodes and scissors are used for sharp dissection. In our experience, curved scissors are mostly used as they provide better ergonomics and better operative field vision especially in a small working space. The needle holder is an important tool in laparoscopic pediatric surgery, where the use of clips is not as frequent as in adult laparoscopic surgery, and knotting becomes an important step in every procedure. There are different types of needle holders depending on the handle and tip design (straight or curved); the most frequently used is the curved tip needle holder.

\section{Unipolar electrode}

This is used for coagulation and dissection. The hook shaped type is mainly used for unipolar cutting and coagulation.

\section{Suction and irrigation instruments}

Suction and irrigation are very important when working in small spaces as it provides a clear field of vision; even if suction is not always required it should be available on standby. In our practice, $3 \mathrm{~mm}$ or $5 \mathrm{~mm}$ cannulas are used depending on the patient's age.

\section{Extraction bags}

The disposable extraction bag is very useful and important in preventing spillage, and contamination during removal of benign or malignant masses. The bag is strong enough to resist tearing during extraction through small openings.

\section{Robotic surgery instrumentation}

The da Vinci surgical system consists of the surgeon's console, the patient-side cart with the interactive robotic arms, the vision cart and the Endowrist robotic instruments. 70,71

\section{Surgeon console}

The surgeon console is a distinct unit from which the robot arms with all their functions may be controlled. The system offers the surgeon a three-dimensional view of the surgical field, in real-time highresolution, through the stereo viewer.

\section{Patient-side cart}

The patient-side cart has three robotic arms and an optional fourth arm (rarely used in infants and young children). One arm holds the endoscope that is connected to the camera. Other arms hold interchangeable surgical instruments that are inserted by the bedside assistant. The da Vinci system uses EndoWrist (Intuitive Surgical, Inc., Sunnyvale, CA) surgical instruments.

\section{Vision cart}

The vision system includes the endoscope, the cameras, and other equipment to produce a $3 \mathrm{D}$ image of the operating field. The endoscope is connected to either a high- or wide-angle camera. The camera head is also connected to an automatic focus control that is linked to the surgeon console; the signal is transferred as a $3 \mathrm{D}$ image, at 10 -fold magnification. The camera is designed to mimic the surgeon's eyes. The optical camera channels are connected to chip camera control units (CCU). The system also has a digital zoom that allows the surgeon to magnify the view of the tissue without moving the endoscope.

\section{EndoWrist instruments}

The EndoWrist ${ }^{\circledR}$ (Intuitive Surgical, Inc., Sunnyvale, CA) surgical instruments, mimic the movements of the human hand and wrist. The endowrist articulation allows precise control in manipulating the tissues. It imitates the human wrist articulation (7 degrees of freedom when using $8 \mathrm{~mm}$ instruments, with $90^{\circ}$ articulation and tremor reduction).

Common instruments used in laparoscopy including needle holders and Maryland dissectors are also used in robotic assisted surgery. Most pediatric gynecologic procedures are performed using an $8.5 \mathrm{~mm}$ camera port and $5 \mathrm{~mm}$ instruments, a needle driver and $5 \mathrm{~mm}$ grasping instruments. ${ }^{14,72}$ The robotic set is listed in Table 5 .

In the pediatric age group, an $8.5 \mathrm{~mm}$ camera $+5 \mathrm{~mm}$ instruments with a longer articulating tip are used in most procedures.

Traditional laparoscopic pediatric instruments may be used through a robotic port or through an accessory 5-mm laparoscopic port. This port may reduce operative times, provide assistance with retraction or suture traction, as well as suction or irrigation, without instrument changes. Finally, this accessory port can be used for the insertion of endobags for mass extraction.

The snake-like movement of the $5 \mathrm{~mm}$ instruments requires more operating space. ${ }^{14}$ However, most gynecologic procedures are performed with grasping forceps, hook cautery, scissors, and needle holders.

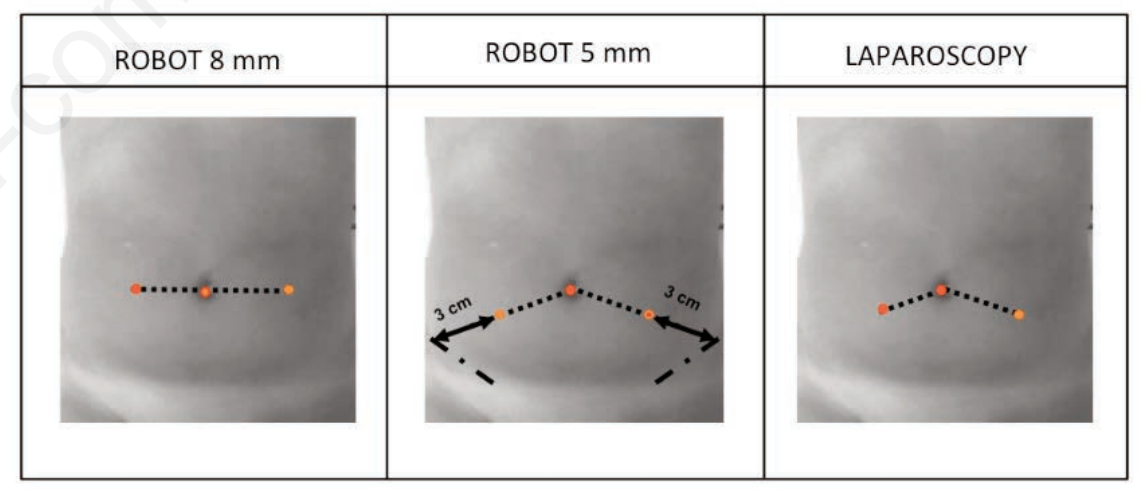

Figure 2. Port placement in minimally invasive surgery.

Table 5. Robotic set $(5 \mathrm{~mm})$ for pediatric gynecological surgery.

\begin{tabular}{ll} 
Instruments & Components \\
Laparoscopic vision tower & Camera, light source, insufflator and the monitor \\
Endoscopes & $8.5 \mathrm{~mm}, 3 \mathrm{D} 2$ built-in lenses, angled $\left(30^{\circ}\right)$ and straight $\left(0^{\circ}\right)$ \\
\hline Cautery Instruments & Hook monopolar cautery $(5 \mathrm{~mm})$ \\
Forceps and grasping instruments & Maryland dissectors and DeBakey forceps $(5 \mathrm{~mm})$; atraumatic bowel graspers $(5 \mathrm{~mm}) ;$ sharp-toothed Schertel graspers $(5 \mathrm{~mm})$ \\
\hline Scissors & Curved scissors $(5 \mathrm{~mm})$ for dissection and cutting and round tip scissors $(5 \mathrm{~mm})$ \\
\hline
\end{tabular}




\section{Single-site $5 \mathbf{~ m m}$ instruments}

A single site port is a device that enables the use of the robotic arms through a single incision. ${ }^{73}$ With the introduction of the single site $5 \mathrm{~mm}$ instruments, the da Vinci software offers a new scareless technology with intuitive movement through crossed canulae, so the controls at the console are switched such that the left actuator is driving the right arm, and vice versa. This eliminates the confusion with crossed instruments and standard LESS. Another advantage is it minimizes cannula collisions and movement of the ports. The curved $5 \mathrm{~mm}$ instruments help separate the robot arms outside the body, thus minimizing collision and optimizing the triangulation. ${ }^{14}$

The five-lumen port, with an $1.5 \mathrm{~cm}$ incision, provides access for two single-site instruments (plus an $8.5 \mathrm{~mm}$ endoscope) and a $5 / 10 \mathrm{~mm}$ accessory port and insufflation adaptor.

The port is inserted via the umbilicus using the open Hassan technique. The umbilicus is the most commonly utilized site of entry and provides the best cosmetic results.

\section{Port placement}

Port placement in laparoscopy and robotic surgery is illustrated in Figure 2. In the robotic approach, port placement is crucial to accommodate the instruments and represents the most challenging aspect to maximize movement and prevent collisions of the external robotic arms, particularly in small children in which a limited working space is typical. ${ }^{14}$

The slightest variation in port site insertion even millimetric can produce limited mobility of the instruments, thus producing robot arm conflicts and may jeopardize the safety of the procedure. The insertion site requires a wider angulation in comparison with mini access surgery, especially when using $5 \mathrm{~mm}$ instruments with less dexterity than the $8 \mathrm{~mm}$ instruments. The maximum distance between trocars will benefit the dexterity of the surgeon. Working ports should also be placed at a sufficient distance (at least $3 \mathrm{~cm}$ ) from the superior iliac spine and costal margin in the lower and upper abdomen respectively. ${ }^{14}$ Others have found an inverse relationship between the anterior superior iliac spine (ASIS) distance and the puboxyphoid (PXD) distance and mobility of the robotic instruments using a cutoff of $13 \mathrm{~cm}$ for the ASIS and $15 \mathrm{~cm}$ for PXD. 74

\section{Pneumoperitoneum}

Low insufflation pressure should be maintained, usually $6-8 \mathrm{~mm} \mathrm{Hg}$ is sufficient and should not exceed $10 \mathrm{mmHg}$ pressures or more than a $2 \mathrm{~L}$ insufflating volume of $\mathrm{CO}_{2}$. In Robotic assisted surgery the pressures are even lower as the traction upward exercised by the scope provides more working space, thus lower pressures are needed. 6

\section{Other considerations for minimally invasive pediatric gynecology}

Gynecological conditions are unique in both presentation and management in the pediatric population. Although many cases necessitating surgical gynecologic needs in the past were managed by the pediatric surgeon alone, nowadays surgical planning is often managed by a multidisciplinary team that can involve pediatric and adolescent gynecologists, gynecologic oncologists and urologists. Whenever a surgical procedure is proposed for a child or adolescent, adequate perioperative and operative considerations are mandatory. 75

Counseling prior to surgery is mandatory and should involve both of the parents and the patient, if age appropriate. During this discussion, the risks, benefits, and alternatives to surgery should be conveyed and documented. Many hospitals have educational resources that can help both providers and parents talk with children about the upcoming surgery, which can decrease anxiety for all involved. 15

Antimicrobial prophylaxis in surgery is equally as important in the pediatric and adolescent patient as it is in adult patients. ${ }^{76}$ However, deep vein thrombosis (DVT) prevention during the perioperative interval must be avoided in patients less than 14 years old because of the low risk of DVT in this group, 75,77 and chemical prophylaxis with heparin or enoxaparin are reserved for those deemed at high risk based on a combination of personal and hereditary risk factors. ${ }^{75,77}$ Sufficient pain management during postoperative recovery is recommended as in adults. ${ }^{75}$

\section{References}

1. Lauterbach R, Matanes E, Lowenstein L. Review of Robotic Surgery in Gynecology-The Future Is Here. Rambam Maimonides Med J 2017;28:8.

2. Alkatout I, Mettler L, Maass N, et al. Robotic surgery in gynecology. J Turk Ger Gynecol Assoc 2016;17:224.

3. Bouquet de Joliniere J, Librino A, Dubuisson JB, et al. Robotic Surgery in
Gynecology. Front Surg 2016;3:26.

4. Sinha R, Sanjay M, Rupa B, et al. Robotic surgery in gynecology. J Minim Access Surg 2015;11:50.

5. Liu H, Lawrie TA, Lu D, et al. (). Robotassisted surgery in gynaecology. Cochrane Database Syst Rev 2014;12: CD011422.

6. Nakib G, Calcaterra V, Scorletti F, et al. Robotic assisted surgery in pediatric gynecology: promising innovation in mini invasive surgical procedures. J Pediatr Adolesc Gynecol 2013;26:e5-7.

7. Cundy TP, Marcus HJ, Hughes-Hallett A, et al. Robotic surgery in children: adopt now, await, or dismiss? Pediatr Surg Int 2015;31:1119.

8. Alqahtani A, Albassam A, Zamakhshary $M$, et al. Robot-assisted pediatric surgery: how far can we go? World J Surg 2010;34:975.

9. Marhuenda C, Ginie C, Asensio M, et al. Robotic surgery: first pediatric series in Spain. Cir Pediatr 2011;24,90.

10. Gutt CN, Markus B, Kim ZG, et al. Early experiences of robotic surgery in children. Surg Endosc 2002;16:1083.

11.van Haasteren G, Levine S, Hayes W. Pediatric robotic surgery: early assessment. Pediatrics 2009;124:1642.

12. Bhandari A, Hemal A, Menon M. Instrumentation, sterilization, and preparation of robot. Indian $\mathrm{J}$ Urol 2005;21:83.

13. Hortman C, Chung S. Positioning Considerations in Robotic Surgery. AORN J 2015;102:434.

14. Pelizzo G, Nakib G, Romano P, et al. Five millimetre-instruments in paediatric robotic surgery: Advantages and shortcomings. Minim Invasive Ther Allied Technol 2015:24,148.

15. Broach AN, Mansuria SM, Sanfilippo JS. Pediatric and adolescent gynecologic laparoscopy. Clin Obstet Gynecol 2009;52,380.

16. Bergeron LM, Bishop KC, Hoefgen HR, et al. Surgical Management of Benign Adnexal Masses in the Pediatric/Adolescent Population: An 11Year Review. J Pediatr Adolesc Gynecol 2017;30:123.

17. Helmrath M, Shin C, Warner B. Ovarian cysts in the pediatric population. Semin Pediatr Surg 1998;7:19.

18. Cass D, Hawkins E, Brandt M, et al. Surgery for ovarian masses in infants, children, and adolescents: 102 consecutive patients treated in a 15-year period. J Pediatr Surg 2001;36:693.

19. Hermans AJ, Kluivers KB, Wijen MH, et al. Diagnosis and treatment of adnexal masses in children and adolescents. Obstet Gynecol 2015;125:611. 
20. Kelleher CM, Goldstein AM. Adnexal masses in children and adolescents. Clin Obstet Gynecol 2015;58:76.

21. Pfeifer S, Gosman G. Evaluation of adnexal masses in adolescents. Pediatr Clin North Am 1999; 46:573.

22. Péroux E, Franchi-Abella S, SainteCroix D, et al. Ovarian tumors in children and adolescents: a series of 41 cases. Diagn Interv Imaging 2015;96:273.

23. Rogers EM, Casadiego CG, Lacy J, et al. Preoperative risk stratification of adnexal masses: can we predict the optimal surgical management? J Pediatr Adolesc Gynecol 2014;27:125.

24. Łuczak J, Bagłaj M. Selecting treatment method for ovarian masses in children 24 years of experience. J Ovarian Res 2017;10:59.

25. De Backer A, Madern GC, Oosterhuis $\mathrm{JW}$, et al. Ovarian germ cell tumors in children: a clinical study of 66 patients. Pediatr Blood Cancer 2006;46:459.

26. Amies Oelschlager AM, Gow KW, Morse CB, et al. Management of large ovarian neoplasms in pediatric and adolescent females. J Pediatr Adolesc Gynecol 2016;29:88.

27. Ali A, Sayed H, Salem M, et al. Clinicopathological pattern and outcome of pediatric malignant ovarian germ cell tumors: South Egypt Cancer Institute experience. J Pediatr Surg. 2017:S00223468.

28. Cecchetto G. Gonadal germ cell tumors in children and adolescents. J Indian Assoc Pediatr Surg 2014; 19:189.

29. Strickland J. Ovarian cysts in neonates, children and adolescents. Curr Opin Obstet Gynecol 2002;14:459.

30. Berger-Chen S, Herzog TJ, Lewin SN, et al. Access to conservative surgical therapy for adolescents with benign ovarian masses. Obstet Gynecol 2012;119:270.

31. Ozcan R, Kuruoglu S, Dervisoglu S, et al. Ovary-sparing surgery for teratomas in children. Pediatr Surg Int 2013;29:233.

32. Lin $\mathrm{X}, \mathrm{Wu} \mathrm{D}$, Zheng N, et al. Gonadal germ cell tumors in children: A retrospective review of a 10-year singlecenter experience. Medicine (Baltimore) 2017;96:e7386.

33. Brookfield K, Cheung M, Koniaris L, et al. A population-based analysis of 1037 malignant ovarian tumors in the pediatric population. J Surg Res 2009; 156:45.

34. Oltmann SC, Garcia N, Barber R, et al. Can we preoperatively risk stratify ovarian masses for malignancy? J Pediatr Surg 2010;45:130.
35. Billmire D, Vinocur C, Rescorla F, et al. Children's Oncology Group (COG). Outcome and staging evaluation in malignant germ cell tumors of the ovary in children and adolescents: an intergroup study. J Pediatr Surg 2004;39:424.

36. Terenziani M, Bisogno G, Boldrini R, et al. Malignant ovarian germ cell tumors in pediatric patients: The AIEOP (Associazione Italiana Ematologia Oncologia Pediatrica) study. Pediatr Blood Cancer 2017;64.

37. Gupta B, Guleria K, Suneja A, et al. Adolescent ovarian masses: A retrospective analysis. J Obstet Gynaecol 2016;36:515.

38. Reiter MJ, Schwope RB, Lisanti CJ. Algorithmic approach to solid adnexal masses and their mimics: utilization of anatomic relationships and imaging features to facilitate diagnosis. Abdom Imaging 2014;39:1284.

39. Heo SH, Kim JW, Shin SS, et al. Review of ovarian tumors in children and adolescents: radiologic-pathologic correlation. Radiographics 2014;34: 2039.

40. ACOG Committee. Adnexal torsion in adolescents: ACOG Committee Opinion No, 783 Summary. Obst Gynecol 2019;134,:435.

41. Lucidi A, Chiantera V, Gallotta V, et al. Role of robotic surgery in ovarian malignancy. Best Pract Res Clin Obstet Gynaecol 2017:S1521-6934.

42. Tse KY, Ngan HYS, Lim PC. Robotassisted gynaecological cancer surgery-complications and prevention. Best Pract Res Clin Obstet Gynaecol 2017:30063.

43. Li XM, Wang J. Comparison of robotic surgery with laparoscopy for surgical staging of endometrial cancer: a metaanalysis. Zhonghua Fu Chan Ke Za Zhi 2017;52:175.

44. Black AY, Jamieson MA. Adolescent endometriosis. Curr Opin Obstet Gynecol 2002;14:467.

45. American College of Obstetricians and Gynecologists, "ACOG Committee Opinion": Endometriosis in adolescents. Obstet Gynecol 2005;105:921.

46. Goldstein DP, De Cholnoky C, Emans SJ. Adolescent endometriosis. J Adolesc Health Care 1980;1:37.

47. Laufer MR, Goitein L, Bush M, et al. Prevalence of endometriosis in adolescent girls with chronic pelvic pain not responding to conventional therapy. J Pediatr Adolesc Gynecol 1997; 10:199.

48. Dowlut-McElroy T, Strickland JL. Endometriosis in adolescents. Curr Opin Obstet Gynecol 2017;29:306.
49. Zannoni L, Forno SD, Paradisi R, et al. Endometriosis in Adolescence: Practical Rules for an Earlier Diagnosis. Pediatr Ann 2016;45:e332.

50. Stuparich MA, Donnellan NM, Sanfilippo JS. Endometriosis in the Adolescent Patient. Semin Reprod Med 2017;35,102.

51. Ahn SH, Singh V, Tayade C. Biomarkers in endometriosis: challenges and opportunities. Fertil Steril 2017;107:523.

52. Angioni S, Peiretti M, Zirone $\mathrm{M}$ et al. Laparoscopic excision of posterior vaginal fornix in the treatment of patients with deep endometriosis without rectum involvement: surgical treatment and long-term follow-up. Hum Reprod 2006;6:1629.

53. Angioni S, Mereu L, Maricosu G, et al. Single port access laparoscopy (SPAL) for endometrioma excision. J Endometr 2010;2:95.

54. Gambone JC, Mittman BS, Munro MG, et al. Consensus statement for the management of chronic pelvic pain and endometriosis: proceedings of an expertpanel consensus process. Fertil Steril 2002;5:961.

55. Nezhat FR, Sirota I. Perioperative outcomes of robotic assisted laparoscopic surgery versus conventional laparoscopy surgery for advanced-stage endometriosis. JSLS 2014;18.

56. Truong M, Kim JH, Scheib S, Patzkowsky K. Advantages of robotics in benign gynecologic surgery. Curr Opin Obstet Gynecol 2016;28:304.

57. Dietrich JE, Millar DM, Quint EH. Obstructive Reproductive Tract Anomalies. Pediatr Adolesc Gynecol 2014;27:396e402.

58. Breech LL, Laufer MR. Mullerian anomalies. Obstet Gynecol Clin North Am 2009;36:47.

59. Ludwin A, Ludwin I, Kudla M, et al. Reliability of the European Society of Human Reproduction and Embryology/European Society for Gynaecological Endoscopy and American Society for Reproductive Medicine classification systems for congenital uterine anomalies detected using three-dimensional ultrasonography. Fertil Steril 2015;104:688.

60. Santos XM, Krishnamurthy R, BercawPratt J, et al. The utility of ultrasound and magnetic resonance imaging versus surgery for the characterization of mullerian anomalies in the pediatric and adolescent population. J Pediatr Adolesc Gynecol 2012;25:181.

61. Pellerito JS, McCarthy SM, Doyle MB, et al. Diagnosis of uterine 
anomalies: relative accuracy of MR imaging, endovaginal sonography, and hysterosalpingography. Radiology 1992; 183:795.

62. Kayadibi Y, Ozmen E, Emir H, et al. Subserosal leiomyoma of uterus mimicking an ovarian tumor in adolescent patient. Jpn J Radiol 2014; 32:48.

63. Perkins JD, Hines RS, Prior DS. (2009). Uterine leiomyoma in an adolescent female. J Natl Med Assoc. 101, 61.

64. Lack EE. (1986). Leiomyosarcomas in childhood: a clinical and pathologic study of 10 cases. Pediatr Pathol. 6, 181.

65. Fleming NA, Hopkins L, de Nanassy J, et al. (2009). Mullerian adenosarcoma of the cervix in a 10-year-old girl: case report and review of the literature. $\mathrm{J}$ Pediatr Adolesc Gynecol. 22, e45.

66. Andrade LA, Derchain SF, Vial JS, et al. Mullerian adenosarcoma of the uterus in adolescents. Int J Gynaecol Obstet. 1992;38:119.

67. Menderes G, Nhundu B, Levy K, et al. Robotic Resection of a Symptomatic
Parasitic Leiomyoma From the Obturator Fossa. J Minim Invasive Gynecol 2017:S1553-4650:30312.

68. Kim S, Luu TH, Llarena N, et al. Role of robotic surgery in treating fibroids and benign uterine mass. Best Pract Res Clin Obstet Gynaecol. 2017:S15216934:30060.

69. Hortman C, Chung S. Positioning considerations in robotic surgery. AORN J 2005; 102:434.

70. Narula VK, Melvin SM. 3Robotic surgical $\neg$ systems. In: Patel VR (ed). Robotic urologic surgery. London: Springer-Verlag; 2007. pp 1-5.

71. Bhandari A, Hemal A, Menon M. Instrumentation, sterilization, and preparation of robot. Indian J Urol 2005;21:83.

72. Ballouhey Q, Clermidi P, Cros J, et al. Comparison of 8 and $5 \mathrm{~mm}$ robotic instruments in small cavities : 5 or $8 \mathrm{~mm}$ robotic instruments for small cavities? Surg Endosc 2015;24.

73. Nelson RJ, Chavali JSS, Yerram N, et al. Current status of robotic single-port surgery. Urol Ann 2017;9:217.

74. Finkelstein JB, Levy AC, Silva MV, et al. How to decide which infant can have robotic surgery? Just do the math. J Pediatr Urol 2015;11:170.

75. Casey J, Yunker A, Anderson T. Gynecologic Surgery in the Pediatric and Adolescent Populations: Review of Perioperative and Operative Considerations. J Minim Invasive Gynecol 2016;7 .

76. Raffini L, Trimarchi T, Beliveau J, et al. Thromboprophylaxis in a pediatric hospital: a patient-safety and qualityimprovement initiative. Pediatrics 2011;127:1326.

77. Bratzler DW, Dellinger EP, Olsen KM, et al. Clinical practice guidelines for antimicrobial prophylaxis in surgery. Am J Health-Syst Pharm 2013;70:195. 